\title{
ASSESSMENT REFORM IN SCIENCE: FAIRNESS AND FEAR; Benny H. W. Yung
}

\author{
Phillip A. Towndrow
}

Aik Ling Tan

\section{BOOK REVIEW}

Printed in the Netherlands by Springer

Date of publication 2006

ISBN 1-4020-3374-5 (HB)

ISBN 978-1-4020-3374-2 (HB)

ISBN 1-4020-3408-3 (e-book)

ISBN 978-1-4020-3408-4 (e-book)

Set against the background of changes in work organization and technology, a recurrent concern for social and cultural planners is how to identify and address objectives in an unstable and unpredictable world. For many, education is a key lever for social, cultural and political change and the periodic (often frequent) restructuring of an educational system is justified as a way of dealing with present and future economic and social demands (cf. Lauder, 1997).

One area of increasing interest and concern for those who are both involved in and subject to educational reform is the shift towards using assessment as a tool for improving teaching and learning. This movement, as noted by Black and Wiliam (1998), turns attention away from restricted forms of testing where there are imperceptible links to learning experiences towards more rounded and learning-based procedures. This phenomenon is exemplified most aptly by changes in the assessment of practical work in science where there is growing appreciation of the limits of one-time, high-stakes, practical examinations. In an effort to grow and improve practices, school-based marks and assessment systems relating to laboratory work are in the ascendancy. But while these efforts resonate with international initiatives that foresee science classrooms as sites of student-centred inquiry, more needs to be known about whether teachers have the capacity to understand and enact the reforms that are passed down from on high as designed and expected.

Benny Yung's book titled, Assessment Reform in Science: Fairness and Fear, is a report of research findings relating to teacher professional development and the concordance of teachers' knowledge and beliefs about science (specifically the nature of science), the purpose of 
practical work and science pedagogy in the enactment of mandated assessment reform. Situated within the Hong Kong education system - a context which is described as 'examination-led'Yung offers a case-driven account of how ten teachers taught and assessed advanced-level biology at high-school level through a continuous marks-based scheme called the Teacher Assessment Scheme or TAS for short.

Yung's study was guided at the outset by one broad and four ancillary questions which need to be borne in mind continually if one is to make full sense of the researcher's rich descriptions and detailed analyses. The main question was (page 4): What relationship existed among (i) secondary science teachers' classroom practice, (ii) secondary science teachers' beliefs about science, teaching and learning, and (iii) their understanding of the school-based assessment reform in practical science? The sub-level inquires were (page 5):

1. What were the characteristic features of secondary science teachers' classroom actions in TAS?

2. What personal understanding/perceptions did secondary science teachers have of TAS (in the context of classroom teaching)?

3. What were the secondary science teachers' beliefs about science, teaching and learning?

4. What were the relationships among teachers' beliefs about science, teaching and learning, their understanding of the TAS reform, and the ways they implemented the reform inside their classrooms?

It is the researcher's hope that his responses to these questions will convey to readers the context of his study and assist in the identification and subsequent understanding of variables that impact on teachers' attempts to adapt in the face of a changing assessment landscape.

In total, the book is made up of fifteen chapters and includes two appendices which explain the theory underlying and methodology of the study in detail. There is a complete list of references, an index and a highly complementary foreword contributed by Professor Derek Hodson of the Ontario Institute of Studies in Education at the University of Toronto, Canada.

The first three chapters provide an introduction to the topic of research and its treatment. In Chapter One, Yung explains the background to the study and its rationale. Data sources are identified and methods of analysis are overviewed in a non-technical, approachable manner. A number of suggestions are made concerning the use of the book and the order in which the chapters could be read depending on the reader's purposes(s). Following Chapter Two, which provides information about the Hong Kong educational system and TAS, Chapter Three presents a largely quantitative portrait of how the researcher's informants enacted TAS. The principal unit of analysis proposed is the frequency of dialogic interactions between teachers and students during the conduct of practical work. The major finding reported is that teachers who were more 
concerned with assessment related issues in their laboratories tended to interact less often with their students than those teachers who were not. The pedagogic and conceptual implications ensuing from this discovery are developed and exploited in the rest of the book.

In Chapters Four to Eleven, eight narrative-based case studies are presented that describe teachers' personal, educational and professional backgrounds, their espoused beliefs about science, practical work and pedagogy and characteristic features of their classroom practices. Each case is supported with interview and lesson transcripts and includes a useful summary at the end.

It is immediately noticeable that the teachers' practices in the case studies are markedly different but this effect is deliberate and managed. Each case can be seen to move along a continuum of practice that might be best described as learning or pedagogically focused at one end towards instruction and assessment focused at the other. Later, Yung attempts to transcend this dichotomy by offering a more nuanced and subtle view of his data but elements of divergent practice persist.

As far as the cases are concerned, Allan (Chapter Four) is portrayed as idealistic and enthusiastic. His focus was to cultivate a pragmatic attitude in his students by prompting them to think, cooperate and solve problems. Allan's enacted practice is said to match his espoused beliefs particularly well. He interacted the most with his students and allowed them to discuss among themselves. He offered assistance on an individual basis believing that the TAS regulations gave him the warrant to do so in the name of promoting investigative work.

John (Chapter Eleven) on the other hand placed a lot of emphasis on preparing students for public exams. Through his transmission approach he used TAS to convey information and rank students according to their ability to conduct practical work under the strictest of conditions.

And then, somewhere in between Allan and John lies Dawn. She is depicted in Chapter Seven as a friendly visionary who wanted to get her students through their exams but at the same time valuing the learning of science for its own sake. Interestingly, the narrative about Dawn (not Dawn's narrative, it is important to note) is perhaps the most appealing. We are told that she was skeptical of TAS at the beginning, but modified her view once she began to reconstruct her teaching practices based on her students' feedback. There is hope here and a signaled way forward about enacting TAS productively.

In Chapter Twelve, Yung offers a preliminary analysis of his cases but this is more than a first cut; it is a carefully constructed link from the previously-presented data to the rest of the book. The pivot is provided when the teachers' combined beliefs and aspirations are reduced and tabulated (see Table12-1, pages 152-155) to further reinforce the tensions that arose when teachers were caught between the dual roles of teaching and assessing in school-based assessment schemes. A key question for subsequent investigation is also drawn out at this point: why were the teachers' interpretations of TAS so different?

Chapter Thirteen presents three differing views of fairness relating to TAS 
implementation mined from the data. It was found that the teachers' discourses were dominated by, and their classroom actions were pre-eminently influenced by, the notion of fairness. However, they did so in three qualitatively different ways: (i) fair in the sense of assessing students on a fair basis; (ii) fair in the sense of not jeopardizing students' chances to learn the subject matter while they are being assessed; and (iii) fair in the sense of not depriving students' of opportunities of receiving all-round education. It was concluded that for teachers to implement the new assessment scheme successfully their existing understanding and beliefs concerning assessment had to be challenged and opportunities provided for them to come to terms with the philosophy of the new assessment scheme. Most importantly, the teachers themselves had to undertake such a learning process.

In our opinion, Chapter Fourteen, 'Teacher Professionalism and Policy Interpretation' is perhaps the most insightful of Yung's analyses. He revisits five of his cases to show the bases upon which his informants derived their interpretations of TAS. What emerge are threshold points in the teachers' capacity to make discretionary judgements in their classrooms relating to assessment. To substantiate this point, a binary division is presented this time between teachers who were either low in confidence and self-worth motivated to those who used the assessment reforms to generate learner and learning-based solutions to classroom challenges.

Chapter Fifteen recaps the research questions and presents an overview of findings in the study. Of particular interest are Yung's views on what could be done to assist teachers in raising teachers' professional consciousness and confidence in dealing with assessment reforms. A role is identified for continuing professional development that engenders collaboration and sustained effort and there is certainly scope for considerable expansion of these notions for both experienced and novice practitioners alike. There is also an identified need for changes in curriculum, pedagogy and assessment to go hand-in-hand; this point has a distinctive ring for readers who know Bernstein (1975).

IIn our opinion, Yung highlights successfully the complex nature of school-based assessments in science practical work. In particular, the excerpts and vignettes presented in each of the chapters are excellent in helping the reader to appreciate and understand the dilemmas and conflicts science teachers can face in the decisions they make in teaching, learning and assessment. Furthermore, the author is commended for the systematic way in which his data were presented and analysed making it easy to compare his informants' beliefs, espoused theories and enacted practices.

Most important and powerful is that this book brings across the many interpretations and realisations of the same policy change that are possible by different teachers. This phenomenon should signal to policy-makers some of the factors that need to be taken into account to ensure the success of school based assessment in science laboratories. Meaningful learning experiences can only be formed if teachers are aware of their own beliefs and also those of others in the same profession. Awareness and comparison can lead to constructive dialogue between teachers which 
will lead, hopefully, to more thoughtful implementation of change. In short, the detailed description provided in this book helps to fill the pedagogic gap between the rhetoric of policy and actual classroom practice. This gap appears to be present in many areas of science education and its reforms these days.

On the downside, the book is somewhat repetitive in places. This is due, in part, to the recursive nature of the researcher's data analysis procedures but it seems to us that each successive sweep through the material depletes its richness and raw vibrancy. That said there is on more than one occasion an invitation from Yung to his audience to take on the role of coanalyst in the interpretation of his data (see page 273). This is an attractive call to participate but one would have to bear in mind that even with the author's care in presenting defensible arguments for his interpretative work, what we, as readers, see of the data is pre-selected and processed. Yung's analytic tools have left permanent marks and subtleties in the cases. Nevertheless, the researcher describes his theoretical framework and data collection methods thoroughly in the appendices. Interested readers, therefore, have sufficient information to consider replicating the work done in their own contexts.

In conclusion, we believe that Yung's book is worth reading. But in light of the author's commitment to contributing to the teacher professional development literature, we contend that the measure of this book will be determined largely by its catalytic impact beyond the context of the reported research findings. Yung's deliberate presentation and sequencing of material is meant, in our opinion, to provoke the reader to not only reflect and evaluate but to act on his or her practices in a transformative manner. In short, this book demands the reader's personal engagement, and we hope for the sake of all learners of science in high schools that this happens.

\section{REFERENCES}

Bernstein, B. (1975). On the curriculum. In Towards a theory of educational transmissions: Volume III - Class, codes and control. (pp. 79-84). London: Routledge and Kegan Paul.

Black, P., \& Wiliam, D. (1998). Assessment and classroom learning. Assessment in Education: Principals, Policy \& Practice, 5(1), 7-74.

Lauder, H. (1997). Education, democracy, and the economy. In A. H. Halsey, H. Lauder, A. L. Brown \& A. S. Wells (Eds.), Education: Culture, economy, and society (pp. 382-392). Oxford: Oxford University Press.

\section{Phillip A. Towndrow and Tan Aik Ling}

The reviewers are researchers in the Centre for Research in Pedagogy and Practice, National Institute of Education, Nanyang Technological University, Singapore. They are involved separately and collaboratively in studies relating to science education, science assessment and teacher professional development. 